\title{
Comparison of plate fixation vs. intramedullary fixation for the management of mid-shaft clavicle fractures: A systematic review and meta-analysis of randomised controlled trials
}

\author{
WEINA JU ${ }^{1}$, SAYID OMAR MOHAMED ${ }^{2}$ and BAOCHANG QI ${ }^{3}$ \\ ${ }^{1}$ Department of Neurology and Neuroscience Center, The First Hospital of Jilin University, Changchun, Jilin 130021, \\ P.R. China; ${ }^{2}$ Department of Orthopedics, Jazeera University Hospital, Mogadishu BN SO 935, Somalia; \\ ${ }^{3}$ Department of Orthopedic Traumatology, The First Hospital of Jilin University, Changchun, Jilin 130021, P.R. China
}

Received January 15, 2020; Accepted May 22, 2020

DOI: $10.3892 /$ etm.2020.9002

\begin{abstract}
A number of meta-analyses have compared clinical outcomes following plate vs. intramedullary fixation for midshaft clavicle fractures (MSCF), but with conflicting results. There is a requirement for updated level-1 evidence to guide clinicians managing MSCF. The aim of the present systematic review and meta-analysis was to compare clinical outcomes following plate vs. intramedullary fixation of MSCF. The PubMed, Scopus, BioMed Central, Cochrane Central Register of Controlled Trials and Google Scholar databases were searched for records added until 1st July 2019. A total of 10 randomised controlled trials (RCTs) were included. Shoulder function was assessed using the Constant-Murley Shoulder Outcome questionnaire and the Disabilities of the Arm, Shoulder and Hand questionnaire (DASH). There was no statistically significant difference in Constant-Murley scores between plate and intramedullary fixation [Mean difference $(M D)=0.75 ; 95 \%$ CI: -2.49 to $\left.3.99 ; P=0.65 ; I^{2}=85 \%\right]$. Similarly, there was no statistically significant difference in DASH scores between the two groups $(\mathrm{MD}=1.55 ; 95 \% \mathrm{CI}$ : -1.12 to 4.23 ; $\left.\mathrm{P}=0.26 ; \mathrm{I}^{2}=89 \%\right)$. There was no statistically significant difference in complications requiring non-routine surgery between plate and intramedullary fixation [risk ratio $(\mathrm{RR})=1.80$, 95\%CI: $0.80-4.05, \mathrm{P}=0.15 ; \mathrm{I}^{2}=0 \%$ ]. There was an increased risk of complications that did not require non-routine surgery with plate fixation as compared to intramedullary fixation ( $\mathrm{RR}=2.38$, 95\% CI: 1.22-4.62, $\mathrm{P}=0.01 ; \mathrm{I}^{2}=70 \%$ ). Plate fixation was also associated with an increased risk of infection and complications of cosmetic dissatisfaction. The present results indicated no difference in long-term functional outcomes
\end{abstract}

Correspondence to: Dr Baochang Qi, Department of Orthopedic Traumatology, The First Hospital of Jilin University, 1 Xinmin Street, Changchun, Jilin 130021, P.R. China

E-mail: qibaochang1@163.com

Key words: midshaft clavicle fracture, plate fixation, intramedullary fixation, Open reduction and Internal fixation between plate and intramedullary fixation of MSCF. Plate fixation was associated with an increased risk of complications not requiring non-routine surgery. Further high-quality RCTs shall strengthen the evidence on this subject.

\section{Introduction}

Clavicle fractures account for $5 \%$ of all fractures in adults and are usually as a result of sports-associated accidents or motor vehicle collisions (1). Approximately $80 \%$ of clavicular fractures involve the midshaft and $>70 \%$ of such fractures are usually displaced $(2,3)$. Traditionally, midshaft clavicular fractures (MSCF) have been treated non-surgically, as early evidence suggested that clavicular non-unions were rare and clavicular malunion, observed radiographically, was clinically irrelevant (4). However, since higher non-union rates and increased functional deficits following non-operative management of displaced MSCF were reported more recently, there has been a gradual shift towards internal fixation as a treatment alternative for MSCF (5).

A number of plate and intramedullary fixation devices have been used to hasten recovery and early return to daily activities following MSCF. However, the optimal fixation method remains a matter of debate (6). Plate fixation provides immediate rigid fixation with rotational stability and may be less technique-sensitive. However, hypertrophic scarring, skin irritation due to implant prominence, infections and implant failure are potential drawbacks (7). On the other hand, intramedullary fixation is less invasive with comparatively reduced implant prominence and better cosmetic results. However, it has certain disadvantages, including the requirement of intra-operative radiation exposure, injury to neurovascular structures and the need for implant removal to prevent migration (8).

A number of meta-analyses, published in the years 2015-16, have compared clinical outcomes following plate vs. intramedullary fixation of MSCF (6,9-12). The results of these meta-analyses, however, have been conflicting. Certain reviews suggested that intramedullary fixation is superior to plate fixation in the management of MSCF (10-12), while others reported no significant differences $(9,13)$. The conflicting 
results among previous studies have resulted in dilemmas for clinicians looking for level-1 evidence to choose between the different fixation methods for MSCF. In view of the discordant results of previous meta-analyses and new trials published thereafter $(14,15)$, there was a requirement for a more robust and updated systematic review and meta-analysis comparing clinical outcomes following plate vs. intramedullary fixation of MSCF, which was provided by the present study.

\section{Data and methods}

Literature search strategy and inclusion criteria. The present systematic review and meta-analysis was performed in accordance with the recommendations of the Preferred Reporting Items for Systematic Reviews and Meta-analyses statement (16) and the Cochrane Handbook for Systematic Reviews of Intervention (17). The Population, Intervention, Comparison, Outcome and Study design outline was used for including studies (16). The following studies were included: Randomised controlled trials (RCTs) conducted on adult patients (age, $>18$ years) with MSCF (Population); evaluating any type of plate fixation (Intervention); comparing it with any type of intramedullary fixation (Comparison) and assessing post-operative shoulder function and complications (Outcomes). Quasi-RCTs (trials where the randomisation method was inappropriate, including an alternate/odd-even numbering technique for randomisation) were excluded. In studies where the randomisation method was not described, the corresponding authors were contacted for clarification. In the case of no response, the studies were included in the meta-analysis and marked with 'unclear risk of bias' for randomisation. Non-randomised trials, retrospective studies, case-series and studies not published in the English language were also excluded.

The PubMed, Scopus, BioMed Central, Cochrane Central Register of Controlled Trials and Google Scholar databases were searched for entries from inception up to 1st July 2019. The following key words were used for the literature search: 'Clavicle', 'clavicle fracture', 'surgery', 'intramedullary fixation', 'plate fixation', 'titanium elastic nail', 'fixation', 'randomised controlled trials', 'shoulder function' and 'complications'. In addition, references of selected studies and review papers on the subject were hand-searched to identify any further missed studies.

Data extraction and outcomes. The literature search was performed by two reviewers (SM and WJ) independently. Articles were screened by their titles and abstracts. The articles selected then underwent full-text evaluation for inclusion in the review. Any discrepancies were settled by consensus. Data were extracted from the included trials by two independent reviewers (SM and WJ) using an abstraction form. The following details were extracted: Authors, year of publication, number of participants, inclusion/exclusion criteria, type of fixation used, rehabilitation protocol, shoulder function and complications.

The primary outcome was long-term shoulder function assessed after a follow-up of at least 6 months. The two commonly scored shoulder function questionnaires, the Constant-Murley Shoulder Outcome questionnaire (16) and the Disabilities of the Arm, Shoulder and Hand questionnaire (DASH) (17), were used. Secondary outcomes were the incidence of complications requiring non-routine surgery (termed as treatment failure) and complications not requiring non-routine surgery. This classification was sourced from a previous meta-analysis by Hussain et al (18). Any complication such as non-union, malunion, implant failure/fracture and refracture requiring non-routine re-intervention, was judged as treatment failure. Other complications, including infection, hypertrophic scar, paraesthesia, dysesthesia, skin irritation, implant prominence, any asymptomatic malunion/non-union or any other minor complication not requiring re-intervention were grouped under 'complications not requiring non-routine surgery'. Pin removal and routine hardware removal were not included as complications.

Risk of bias. The quality of included studies was assessed using the Cochrane Collaboration risk assessment tool for RCTs (19). Risk of bias (low, unclear or high) was rated for random sequence generation, allocation concealment, blinding of participants and personnel, blinding of outcome assessment, incomplete outcome data, selective reporting and other biases. A score of 2 was given for low risk of bias, a score of 1 for unclear risk of bias and a score of 0 for high risk of bias. Studies were then categorized depending on the overall score. A score of 0-5 was considered to indicate low quality, a score of 6-10 medium quality and a score of 11-14 high quality.

Statistical analysis. Shoulder function scores were presented as the mean and standard deviation (SD). Complications were presented as the number of events in each group. A random-effects model was used for the meta-analysis. Continuous data were pooled and differences between groups were presented as the mean difference (MD) and 95\% CI. Categorical data were summarised using the Mantel-Haenszel risk ratio (RR) and $95 \% \mathrm{CI}$. The $\mathrm{I}^{2}$ statistic was used to assess heterogeneity, wherein values of $25-50 \%$ denoted low, $50-75 \%$ denoted medium and $>75 \%$ denoted considerable heterogeneity. Review Manager (version 5.3; Cochrane Collaboration) was used for the meta-analysis. A sensitivity analysis was performed to assess the influence of each study on the pooled effect size. By using the one-study-out method, it was evaluated whether deletion of one individual study would significantly change the results of the meta-analysis. A sub-group analysis was performed for studies excluding comminuted fractures.

\section{Results}

Search results and baseline characteristics. In the database search, 1,420 records were retrieved and 1 study was identified through reference searching (Fig. 1). A total of 19 articles were selected for full-text analysis. From these, 9 studies were excluded, including 4 that were quasi-randomized studies utilizing an alternate/odds-even method for randomization (20-23), 3 that were non-randomized studies $(21,24,25)$, 1 that was a combined prospective and retrospective study (26) and 1 study (27) that was a long-term follow-up of a previously published trial (duplicate data). A total of 10 RCTs were finally included in the present systematic review and meta-analysis $(14,15,28-35)$. 


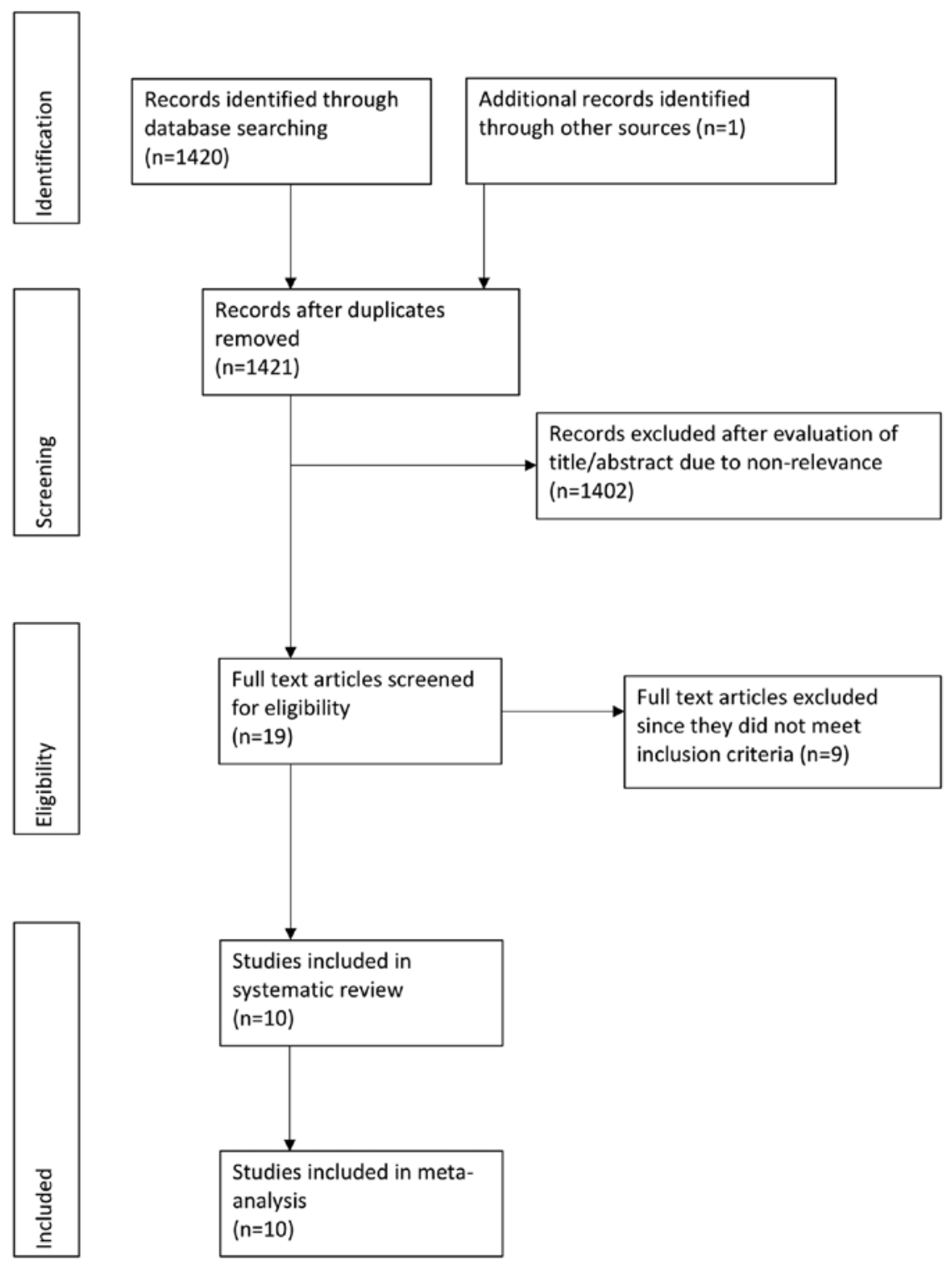

Figure 1. Flow chart of the study retrieval and selection process for the present meta-analysis.

The baseline characteristics of the included studies are presented in Table I. The type of clavicle fracture included was mentioned in six trials (14,29-32,35). All trials were performed on displaced MSCF. Comminuted fractures were included in all studies except for 3 trials $(28,29,34)$. The sample size varied from 15-63 patients per group. The type of plate fixation used was different across studies: Titanium elastic nail was the choice of intramedullary fixation in 7 studies $(15,28-30,32,33,35)$, while 2 utilized a Sonoma CRx Collarbone pin (Sonoma) $(14,31)$ and 1 trial reported on the use of the Rookwood pin (34). Post-operative data were obtained after a follow-up of 12 months in the majority of studies, while 1 study reported follow-up data at 6 months (32).

Primary outcome. A total of 5 studies evaluated shoulder function outcomes using Constant-Murley scores as well as DASH scores $(14,15,30,33,35)$. Shoulder function was assessed exclusively by Constant-Murley scoring in 4 studies $(28,29,32,34)$ and only by DASH scoring in
1 study (31). Data were not presented as the mean and SD by 2 studies $(15,32)$ and attempts to contact the authors were unsuccessful; hence, they were not included in the meta-analysis (Table SI).

Sufficient data on Constant-Murley scores for meta-analysis were available from 7 studies (14,28-30,33-35). Analysis of the pooled data of 215 patients undergoing plate fixation and 216 patients undergoing intramedullary fixation revealed no statistically significant difference in Constant-Murley scores between the two groups ( $\mathrm{MD}=0.75,95 \% \mathrm{CI}:-2.49$ to 3.99 , $\mathrm{P}=0.65 ; \mathrm{I}^{2}=85 \%$; Fig. 2). A sub-group analysis was performed for studies including comminuted clavicle fracture $(\mathrm{MD}=2.66$, 95\% CI: -3.11 to $8.43, \mathrm{P}=0.37 ; \mathrm{I}^{2}=91 \%$ ) and those excluding comminuted fractures (MD=-1.87, 95\% CI: -6.79 to 3.04 , $\mathrm{P}=0.46 ; \mathrm{I}^{2}=77 \%$ ). The overall effect was not significant for both sub-groups (Fig. 2).

Data on the DASH scores were extracted from five studies $(14,30,31,33,35)$. Comminuted fractures were included in all five trials. Pooled scores from 170 patients in the plate fixation group and 171 patients in the intramedullary fixation 


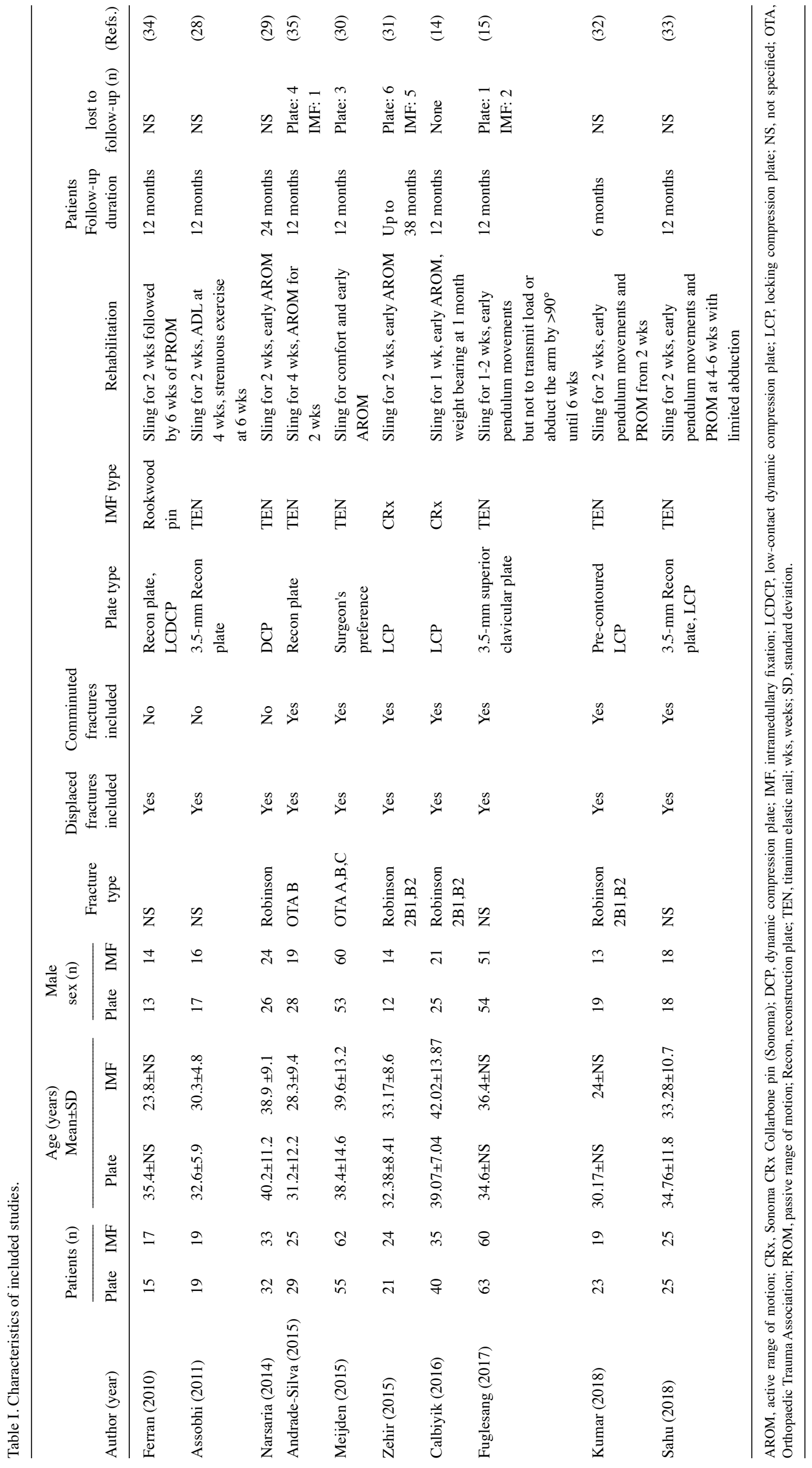




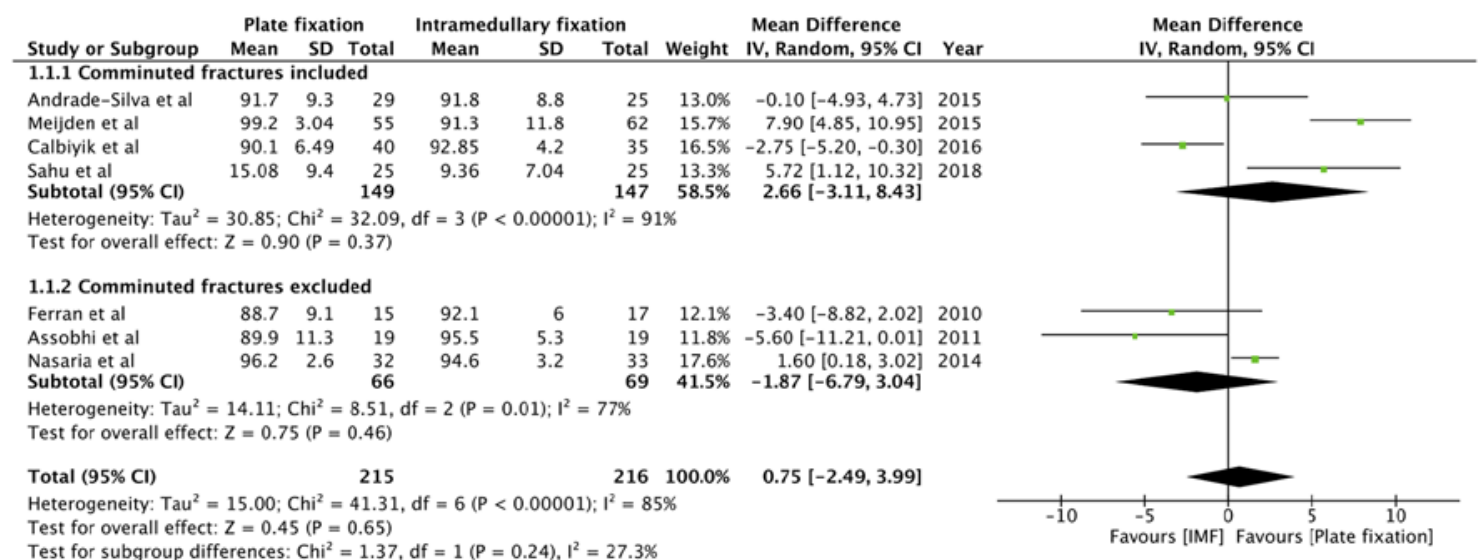

Figure 2. Forest plot for Constant-Murley scores. IMF, intramedullary fixation; SD, standard deviation; IV, inverse variance; df, degrees of freedom.

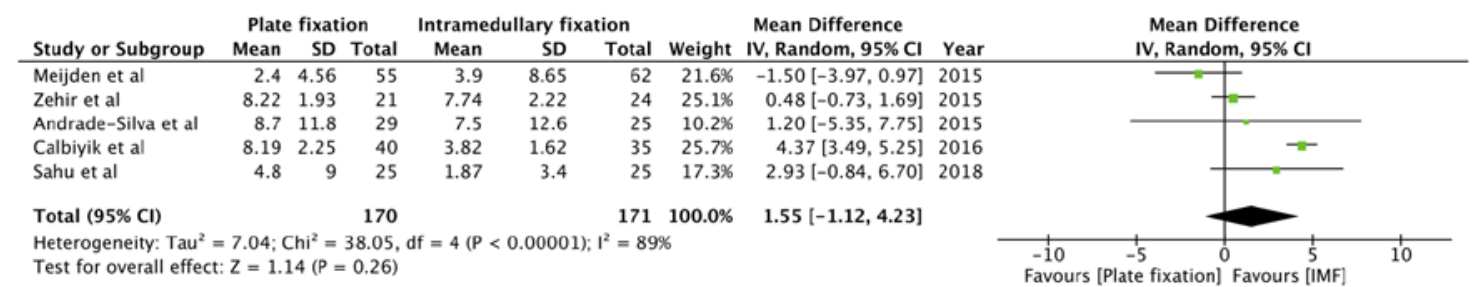

Figure 3. Forest plot for Disabilities of the Arm, Shoulder and Hand questionnaire scores. IMF, intramedullary fixation; SD, standard deviation; IV, inverse variance; $\mathrm{df}$, degrees of freedom.

group demonstrated no statistically significant difference in DASH scores $(\mathrm{MD}=1.55,95 \% \mathrm{CI}:-1.12$ to $4.23, \mathrm{P}=0.26$; $\mathrm{I}^{2}=89 \%$; Fig. 3).

Secondary outcomes. The first secondary outcome was the incidence of treatment failure (i.e., complications requiring non-routine surgery). Causes of treatment failure in the included studies are presented in Table II. While the present analysis indicated that clavicle fractures treated with plate fixation had a 1.8-times greater risk of developing treatment failure, the overall effect was not statistically significant $(R R=1.80$, 95\% CI: 0.80 to $4.05, \mathrm{P}=0.15 ; \mathrm{I}^{2}=0 \%$; Fig. 4). The overall risk in studies excluding comminuted fractures $(\mathrm{RR}=1.71,95 \% \mathrm{CI}$ : 0.35 to $8.38, \mathrm{P}=0.51 ; \mathrm{I}^{2}=0 \%$ ) and those including comminuted fractures (RR=1.84, 95\% CI: 0.72 to $4.70, \mathrm{P}=0.20 ; \mathrm{I}^{2}=0 \%$ ) was also not statistically significant (Fig. 4).

A summary of complications not requiring non-routine surgery reported in the included studies is presented in Table III. Patient-level data were not available from two studies $(15,30)$; hence, they were excluded from the quantitative analysis. The results indicated that plate fixation was associated with a 2.38 -fold increased risk of complications not requiring non-routine surgery, as compared to intramedullary fixation $\left(\mathrm{RR}=2.38,95 \% \mathrm{CI}: 1.22\right.$ to $4.62, \mathrm{P}=0.001 ; \mathrm{I}^{2}=70 \%$; Fig. 5). Sub-group analysis indicated a 2.36 -fold increased risk of complications with plate fixation in both cohorts, i.e., studies excluding comminuted fractures $(\mathrm{RR}=2.36,95 \% \mathrm{CI}$ : 0.98 to $5.70, \mathrm{P}=0.06 ; \mathrm{I}^{2}=22 \%$ ) and studies including comminuted fractures ( $\mathrm{RR}=2.36,95 \% \mathrm{CI}$ : 0.93 to $5.94, \mathrm{P}=0.07$; $\mathrm{I}^{2}=80 \%$ ). The results were close but did not achieve statistical significance in the two sub-groups (Fig. 5).
Meta-analysis was also performed for specific minor complications. Infection rates were reported by 9 studies $(15,28-35)$. With a rate of $7.7 \%$ with plate fixation and $0.7 \%$ with intramedullary fixation, pooled analysis indicated a statistically significant 4.23 -fold increased risk of infection with plate fixation ( $\mathrm{RR}=4.23,95 \% \mathrm{CI}$ : 1.68 to $10.65, \mathrm{P}=0.002$; $\mathrm{I}^{2}=0 \%$; Fig. 6). The risk was increased for studies excluding comminuted fractures $(\mathrm{OR}=5.11,95 \% \mathrm{CI}$ : 1.15 to $22.68, \mathrm{P}=0.03$; $\left.\mathrm{I}^{2}=0 \%\right)$ and those studies including comminuted fractures ( $\mathrm{RR}=3.76,95 \%$ CI: 1.16 to $12.19, \mathrm{P}=0.03 ; \mathrm{I}^{2}=0 \%$; Fig. 6). All complications related to nerve injury (including scar numbness, dysesthesia and paraesthesia) were pooled for quantitative analysis. Meta-analysis indicated a statistically significant 2.74-fold increased risk of nerve injury-related complications with plate fixation ( $\mathrm{RR}=2.74,95 \% \mathrm{CI}: 1.34$ to $5.59, \mathrm{P}=0.006$; $\mathrm{I}^{2}=8 \%$; Fig. 7). Implant-associated complications, including implant protrusion, skin irritation and pain over hardware were reported by eight studies $(14,15,28,30-32,34,35)$. Pooled analysis indicated no statistically significant difference between plate fixation and intramedullary fixation $(R R=0.91$, 95\% CI: 0.51 to $1.62, \mathrm{P}=0.74 ; \mathrm{I}^{2}=55 \%$; Fig. 8). Data on complications of cosmetic dissatisfaction were reported by five studies $(14,28,29,31,33)$. Patients undergoing plate fixation were at a 4.34-fold increased risk of complications of cosmetic dissatisfaction as compared to patients undergoing intra-medullary fixation ( $\mathrm{RR}=4.34,95 \% \mathrm{CI}$ : 1.96 to 9.64 , $\mathrm{P}=0.0003 ; \mathrm{I}^{2}=0 \%$; Fig. 9).

Sensitivity analysis. Sensitivity analysis was performed to evaluate changes in the pooled effect size after removal of one study at a time compared with the entire dataset. It was 
Table II. Treatment failures in included studies.

\begin{tabular}{|c|c|c|c|c|c|}
\hline \multirow[b]{2}{*}{ Author (year) } & \multicolumn{2}{|l|}{ Plate fixation } & \multicolumn{2}{|c|}{ Intramedullary fixation } & \multirow[b]{2}{*}{ (Refs.) } \\
\hline & Complication & Number & Complication & Number & \\
\hline Ferran (2010) & Nil & & Loose hardware & 1 & (34) \\
\hline Assobhi (2011) & $\begin{array}{l}\text { Non-union } \\
\text { Refracture after implant removal }\end{array}$ & $\begin{array}{l}1 \\
1\end{array}$ & Nil & & (28) \\
\hline Narsaria (2014) & Major revision surgery & 2 & Implant failure & 1 & (29) \\
\hline Andrade-Silva (2015) & Implant failure & 1 & Non-union & 1 & $(35)$ \\
\hline Meijden (2015) & $\begin{array}{l}\text { Refracture after implant removal } \\
\text { Non-union } \\
\text { Implant breakage }\end{array}$ & $\begin{array}{l}2 \\
1 \\
1\end{array}$ & Implant failure & 2 & (30) \\
\hline Zehir (2015) & Implant failure & 1 & Implant failure & 1 & $(31)$ \\
\hline Calbiyik (2016) & Implant failure & 2 & Nil & & (14) \\
\hline Fuglesang (2017) & $\begin{array}{l}\text { Deep infection } \\
\text { Refracture }\end{array}$ & $\begin{array}{l}2 \\
1\end{array}$ & $\begin{array}{l}\text { Implant failure } \\
\text { Non-union }\end{array}$ & $\begin{array}{l}1 \\
1\end{array}$ & (15) \\
\hline Kumar (2018) & Nil & & Nil & & $(32)$ \\
\hline Sahu (2018) & $\begin{array}{l}\text { Non-union } \\
\text { Re-fracture after implant removal } \\
\text { Loose hardware }\end{array}$ & $\begin{array}{l}1 \\
1 \\
2\end{array}$ & Nil & & (33) \\
\hline
\end{tabular}

Nil, no treatment failures observed.

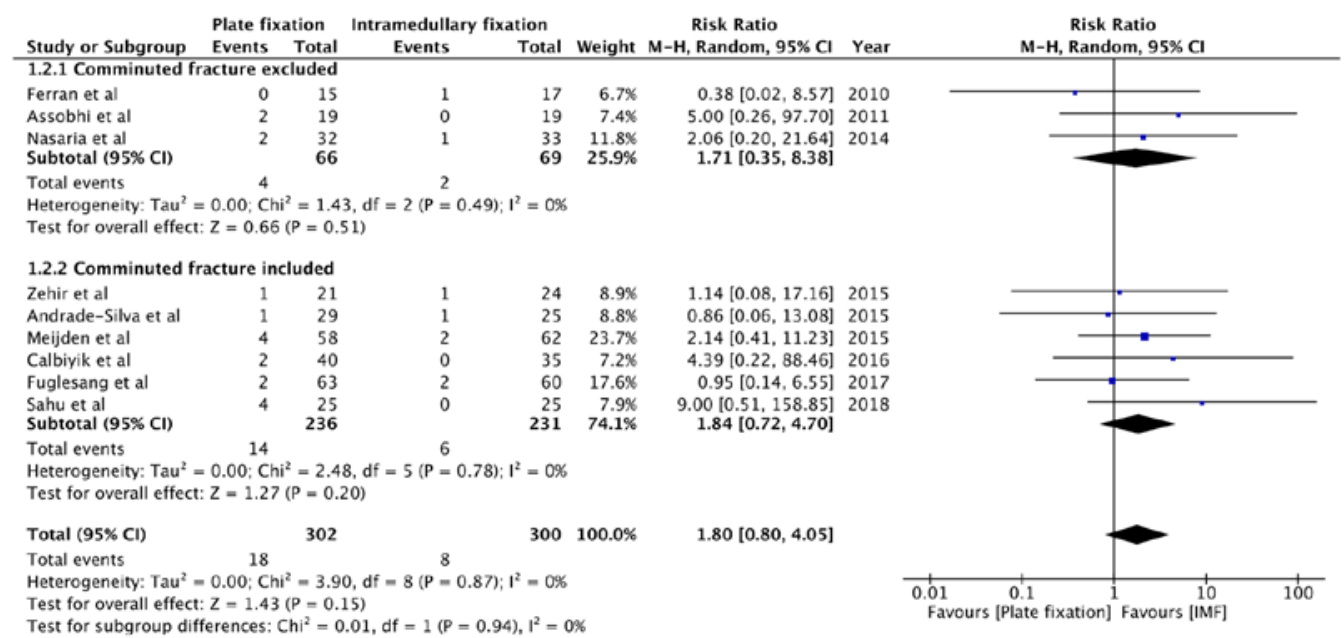

Figure 4. Forest plot for complications requiring non-routine surgery (treatment failure). IMF, intramedullary fixation; M-H, Mantel-Haentzel; df, degrees of freedom.

indicated that when the results of Calbiyik et al (14) and Fuglesang et al (15) were removed sequentially, the overall pooled estimate for nerve injury, while still demonstrating an increased risk with intramedullary fixation, became statistically insignificant [Calbiyik et al (14) excluded: $\mathrm{RR}=2.46,95 \%$ CI: 0.95 to $6.39, \mathrm{P}=0.06 ; \mathrm{I}^{2}=22 \%$ (Fig. S1); and Fuglesang et al (15) excluded: RR=2.40,95\% CI: 0.55 to 10.43 , $\mathrm{P}=0.06 ; \mathrm{I}^{2}=27 \%$ ] (Fig. S2). No changes were observed for any other variables.

Risk of bias. The authors' judgement of risk of bias of included studies is presented in Fig. 10. A total of 3 studies did not clearly specify the method of randomization (32-34). Appropriate methods of allocation concealment were used in 4 studies $(15,30,34,35)$. A high risk of attrition bias was noted in one trial (31). Only three studies were pre-registered with clinical trial registries $(15,30,35)$. Based on the scoring criteria, all studies were rated as being of 'medium quality', except one (32), which was rated as being of 'low quality'. Removal of the 'low-quality' study in the sensitivity analysis did not affect the results for any variable.

\section{Discussion}

In line with the growing trend of operative treatment for MSCF, studies have demonstrated superior results with both plate and intramedullary fixation as compared to non-operative management of MSCF $(5,7)$. However, the choice between the two fixation modalities has remained a matter of debate. To the best of our knowledge, to date, a total of 9 meta-analyses 
Table III. Adverse events not requiring non-routine surgery.

\begin{tabular}{|c|c|c|c|c|c|}
\hline \multirow[b]{2}{*}{ Author (year) } & \multicolumn{2}{|l|}{ Plate fixation } & \multicolumn{2}{|c|}{ Intramedullary fixation } & \multirow[b]{2}{*}{ (Refs.) } \\
\hline & Complication & Number & Complication & Number & \\
\hline \multirow[t]{2}{*}{ Ferran (2010) } & Infection & 3 & Scar numbness & 2 & (34) \\
\hline & Scar numbness & 1 & Soft tissue irritation & 1 & \\
\hline \multirow[t]{3}{*}{ Assobhi (2011) } & Hypertrophic scar & 4 & Prominent implant under & 3 & $(28)$ \\
\hline & Prominent implant under skin & 3 & skin & & \\
\hline & Infection & 1 & Hypertrophic callus & 1 & \\
\hline \multirow[t]{3}{*}{ Narsaria (2014) } & Hypertrophic scar & 4 & Infection & 1 & (29) \\
\hline & Wound dehiscence & 3 & & & \\
\hline & Infection & 2 & & & \\
\hline \multirow[t]{5}{*}{ Andrade-Silva (2015) } & Implant bending & 11 & Implant bending & 1 & (35) \\
\hline & Paraesthesia & 8 & Implant related pain & 10 & \\
\hline & Implant-related pain & 4 & Partial implant migration & 5 & \\
\hline & Partial implant migration & 2 & & & \\
\hline & Infection & 1 & & & \\
\hline \multirow[t]{6}{*}{ Meijden $(2015)^{\mathrm{a}}$} & Infection & 3 & Hematoma & 6 & $(30)$ \\
\hline & Hematoma & 5 & Transient neuropraxia & 1 & \\
\hline & Irritation due to implant protrusion & 25 & Irritation due to implant protrusion & 44 & \\
\hline & Implant breakage & 1 & Implant failure & 2 & \\
\hline & Nonunion & 1 & & & \\
\hline & Refracture after implant removal & 2 & & & \\
\hline \multirow[t]{4}{*}{ Zehir (2015) } & Cosmetic dissatisfaction & 9 & Cosmetic dissatisfaction & 4 & $(31)$ \\
\hline & Skin irritation & 3 & & & \\
\hline & Dysesthesia & 2 & & & \\
\hline & Infection & 1 & & & \\
\hline \multirow[t]{4}{*}{ Calbiyik (2016) } & Cosmetic dissatisfaction & 14 & Cosmetic dissatisfaction & 1 & (14) \\
\hline & Skin irritation & 2 & Implant failure & 2 & \\
\hline & Dysesthesia & 3 & & & \\
\hline & Painful shoulder & 2 & & & \\
\hline \multirow[t]{4}{*}{ Fuglesang $(2017)^{\mathrm{a}}$} & Superficial infection & 5 & Wound dehiscence & 4 & (15) \\
\hline & Incisional numbness & 31 & Incisional numbness & 10 & \\
\hline & Pain over hardware & 26 & Pain over hardware & 19 & \\
\hline & Implant failure & 5 & Implant failure & 1 & \\
\hline \multirow[t]{2}{*}{ Kumar (2018) } & Infection & 1 & Nail impingement & 6 & $(32)$ \\
\hline & Plate prominence & 3 & & & \\
\hline \multirow[t]{3}{*}{ Sahu (2018) } & Infection & 2 & Infection & 1 & (33) \\
\hline & Malunion & 1 & & & \\
\hline & Hypertrophic scar & 3 & & & \\
\hline
\end{tabular}

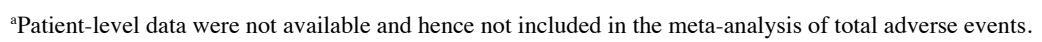

have attempted to compare clinical outcomes after plate vs. intramedullary fixation of MSCF (9-13,18,36-38). The majority of these reports were published in the years $2015(10,12,13,37)$ and $2016(9,11,18,36)$ with the last literature search performed in January 2016 (18). While 4 studies $(9,13,37,38)$ concluded that there is no difference in outcomes after plate or intramedullary fixation of MSCF, the remaining 5 reviews $(10-12,18,36)$ inferred that intramedullary fixation is superior to plate fixation for the management of MSCF. The disparity amongst these studies has been attributed to the different clinical questions, study inclusion/exclusion criteria, data extraction, quality evaluation and statistical methods used for meta-analysis (6). Considering the conflicting results of previous studies and the availability of new trials for inclusion, the present study was performed to provide updated results to clarify this disputed topic.
The results of the present study indicated no difference in long-term functional outcomes after plate or intramedullary fixation of MSCF. These present results are in agreement with those of Hussain et al (18), which did not obtain any such difference from a pooled analysis of 7 RCTs and 3 quasi-RCTs. The study by Houwert et al (9), in which 20 studies (RCTs and cross-sectional studies) were analyzed, also indicated no significant difference in Constant-Murley scores at short-term and long-term follow-ups after MSCF. An earlier analysis demonstrating better shoulder functions with intramedullary fixation may have been incorrect due to the limited number of included studies (10).

It has been indicated that plate fixation is more appropriate for the management of comminuted fractures. Telescoping of the fracture site and limited exercise capacity due to suboptimal stability are observed when markedly comminuted 


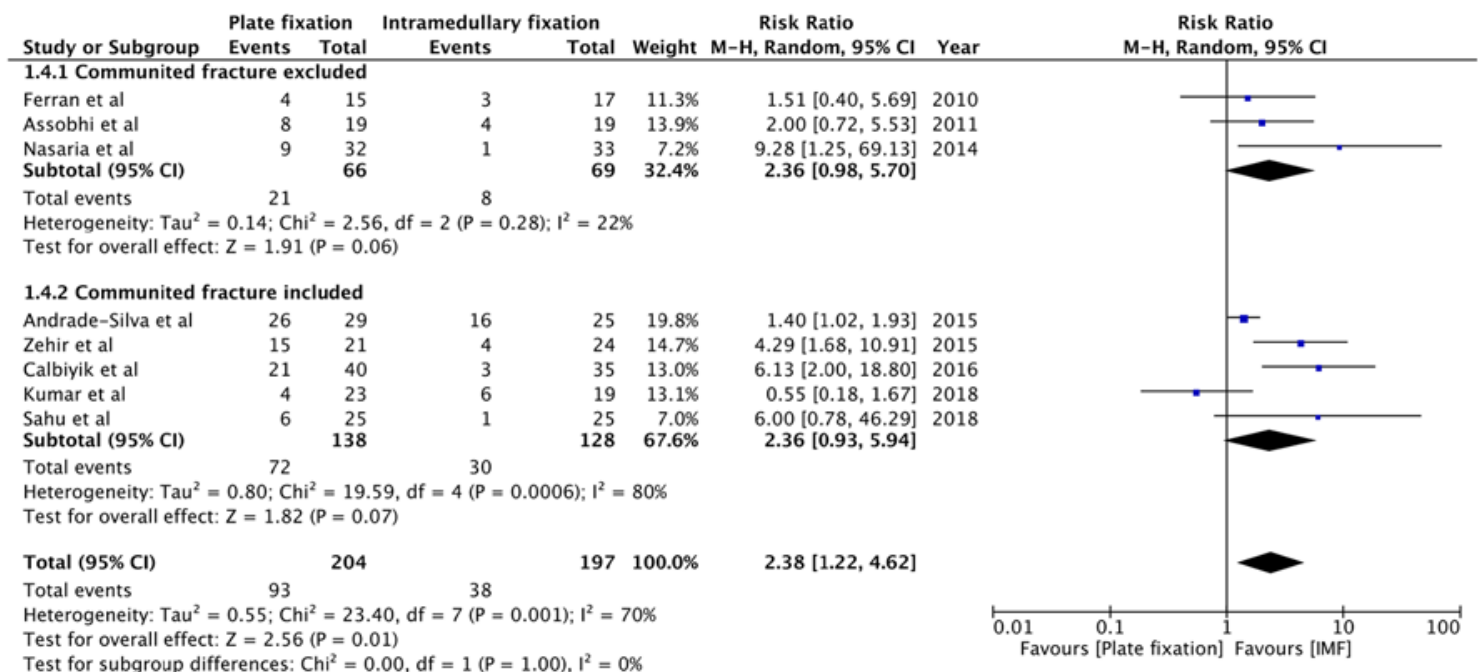

Figure 5. Forest plot for complications not requiring non-routine surgery. IMF, intramedullary fixation; M-H, Mantel-Haentzel; df, degrees of freedom.

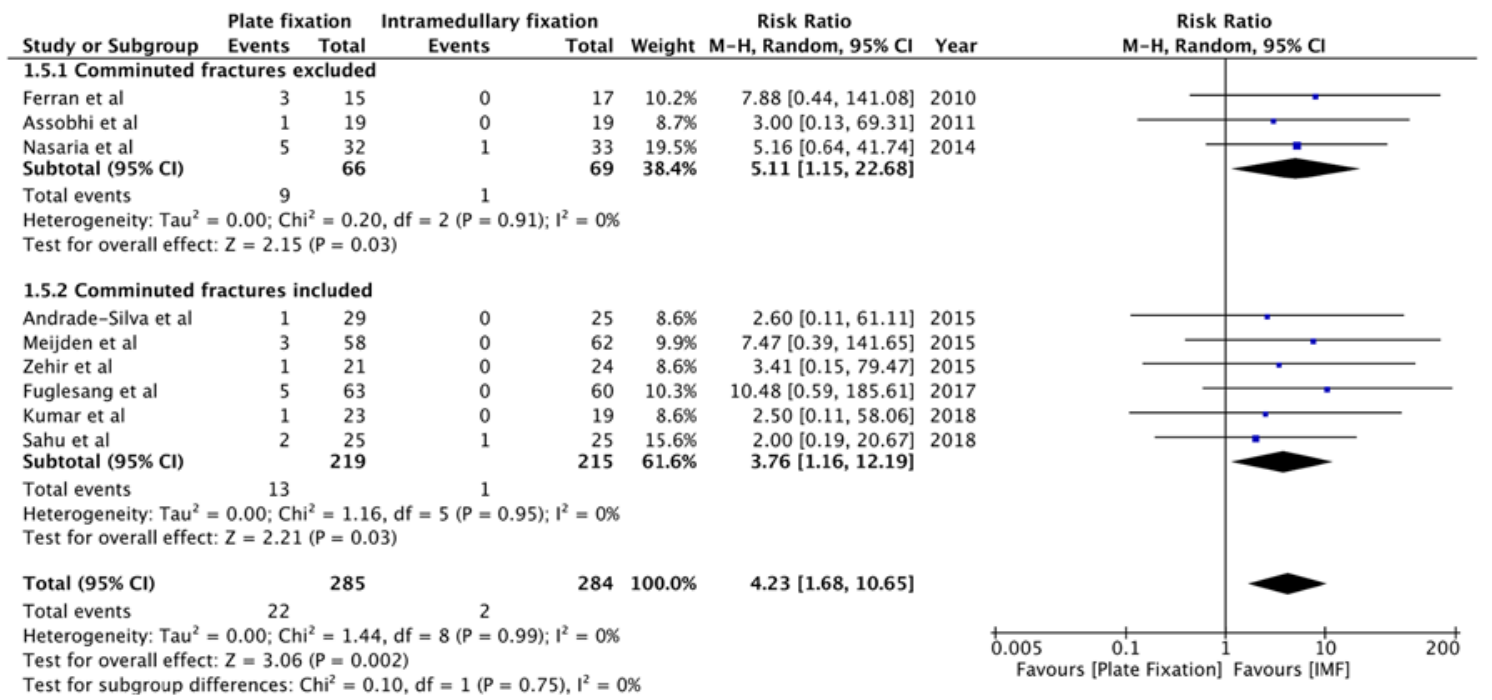

Figure 6. Forest plot for infections. IMF, intramedullary fixation; M-H, Mantel-Haentzel; df, degrees of freedom.

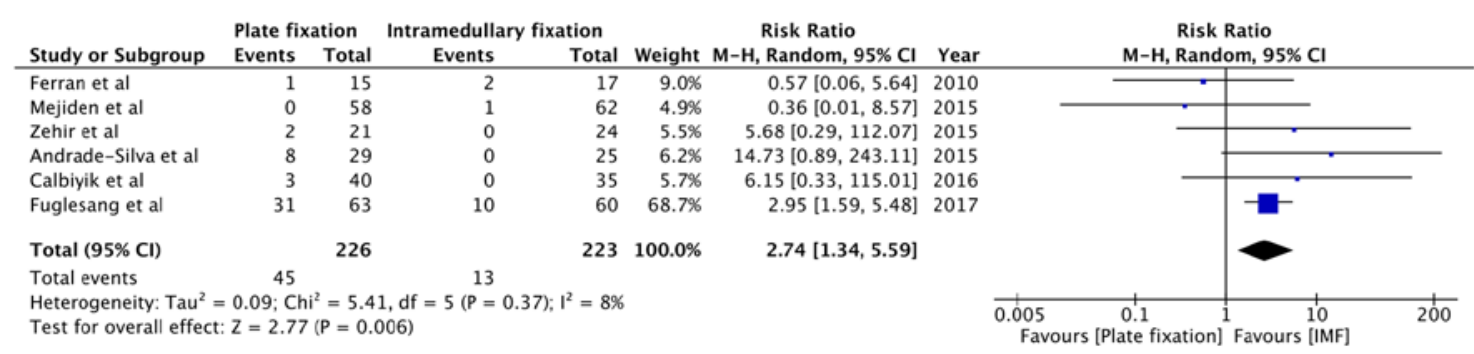

Figure 7. Forest plot for nerve injury-associated complications. IMF, intramedullary fixation; M-H, Mantel-Haentzel; df, degrees of freedom.

fractures are fixed using intramedullary fixation (39). Since 3 RCTs $(28,29,34)$ did not include comminuted fractures, a sub-group analysis was performed in the present study to provide more clarity on the results. There was no statistically significant difference in Constant-Murley scores in the two groups of studies including or excluding comminuted fractures. The RCT by Fuglesang et al (15) indicated that the DASH scores were higher when comminuted fractures were treated with intramedullary fixation. However, this difference was only observed at up to six months of follow-up, with no significant difference in DASH scores between plate and intramedullary fixation at 12 months. It was postulated that, while plate fixation bridges the fracture site to negate the effect of comminution, intramedullary fixation achieves 


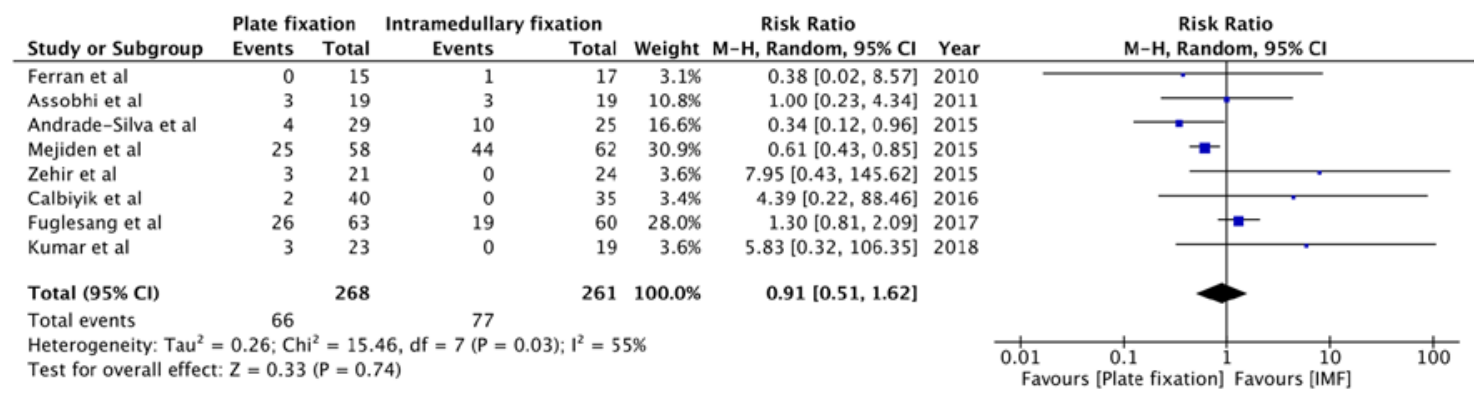

Figure 8. Forest plot for implant-associated complications. IMF, intramedullary fixation; M-H, Mantel-Haentzel; df, degrees of freedom.

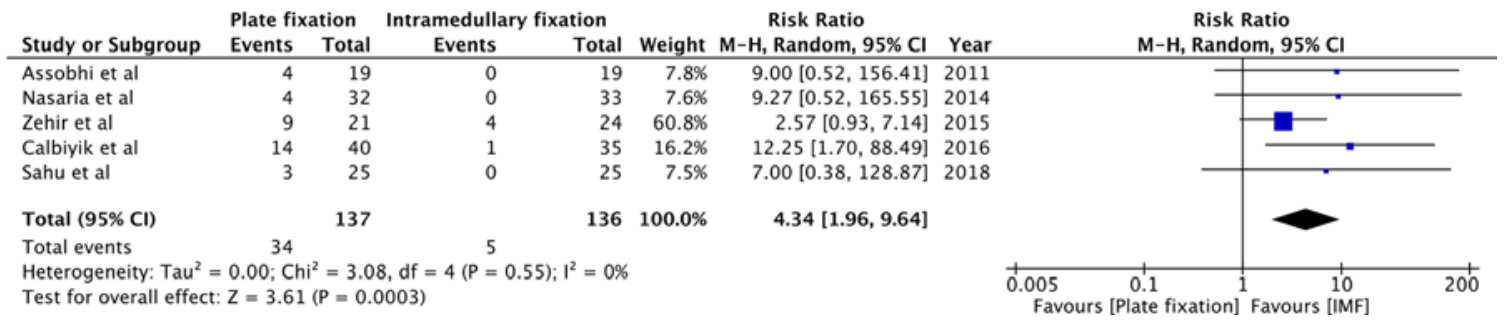

Figure 9. Forest plot for complications of cosmetic dissatisfaction. IMF, intramedullary fixation; M-H, Mantel-Haentzel; df, degrees of freedom.

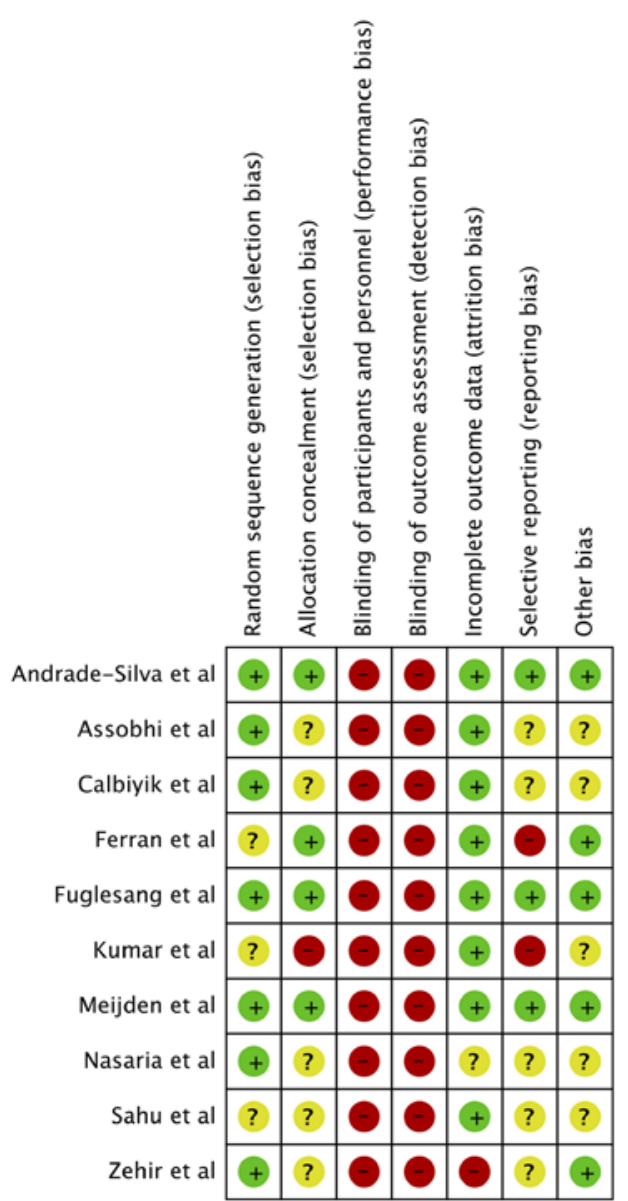

Figure 10. Risk of bias summary.

stability more gradually as the callus consolidates (40). Since only long-term shoulder function scores were pooled in the present study, it was not possible to determine any such differences in early shoulder function. Furthermore, as data on the actual number of comminuted fractures treated were not presented in the included studies, it is not possible to draw any definite conclusions regarding the effect of fracture comminution on clinical outcomes following plate vs. intramedullary fixation of MSCF.

Complications following operative treatment of MSCF are influenced by a number of factors, including patient characteristics (e.g., old age, history of diabetes, drug use, alcohol intake), patient's occupational status (e.g., performance of load-bearing activities), degree of fracture comminution, surgical technique, type of fixation, surgeon's experience and compliance with post-operative instructions $(15,41,42)$. While the influence of baseline patient characteristics is expected to be nullified by appropriate randomization, the results may still be biased considering the methodological heterogeneity and the different types of fixation devices used amongst the included trials. Another limitation is the inconsistent definition and classification of complications across studies. To provide a more comprehensible picture, complications were grouped into those requiring non-routine surgery (treatment failure) and those not requiring non-routine surgery (18). The results of the present study indicated that plate and intramedullary fixation had similar rates of treatment failure. These results concur with a previous meta-analysis of RCTs on this subject, which also reported a non-significant result $(\mathrm{RR}=2.19,95 \% \mathrm{CI}$ : $0.93-5.15, \mathrm{P}=0.07 ; \mathrm{I}^{2}=0 \%$ ) (18). However, it is important to note that the CI of the RR for treatment failure in the present analysis was wide with an upper limit of 4 (denoting a 4-fold risk of complications with plate fixation). The small number of events and limited sample size of individual studies may have influenced the overall results.

In terms of complications not requiring non-routine surgery, the present results indicated that plate fixation is associated with a 2.38 -fold increased risk as compared to intramedullary fixation. The difference may be attributed to the requirement 
for greater exposure, increased surgical time and soft-tissue stripping with plate fixation, which translates into a higher risk of infection, nerve injury and hypertrophic scars $(7,43)$. The present meta-analysis on specific complications supported this notion, as a 4.23 -fold increased risk of infection, 2.74-fold increased risk of nerve injury-associated complications and 4.34 times increased risk of complications of cosmetic dissatisfaction were determined for plate fixation. Although the results of nerve injury-associated complications were skewed in the sensitivity analysis, the CI was relatively wide and the difference became only just insignificant after removal of two particular studies $(14,15)$.

While a large number of reviews were already published on this subject, the present study has the strength of an updated literature search, allowing for inclusion of 4 more RCTs $(14,15,32,33)$ compared with a previous meta-analysis (18). Furthermore, to circumvent the intrinsic bias associated with cross-sectional studies and avoid the higher risk of methodological bias of quasi-randomized trials from influencing the present results, these study types were excluded from the present review. A sub-group analysis based on inclusion of comminuted fractures was also performed for primary and secondary outcomes. However, the present study has certain limitations. Despite the inclusion criteria, the quality of the included studies was not high. Bias with regard to randomization and allocation concealment may have influenced the results. Furthermore, the high degree of methodological heterogeneity, with different types of plates and intramedullary fixation devices used, may have skewed the outcomes. In addition, the influence of varied operator experience and surgical techniques on outcomes cannot be completely excluded. As another limitation, the sample size of the majority of studies was small with only two studies $(15,32)$ including $>50$ patients per group. Finally, as previously discussed, the number of patients with comminuted fractures in the included studies is not known. The impact of this variable on clinical outcomes should be elucidated by further studies.

Despite these limitations, the present study, a meta-analysis of only RCTs, provides the most up-to-date evidence on this controversial topic. Data of 322 patients randomized to receive plate fixation and 319 patients randomized to receive intramedullary fixation for MSCF were pooled in the present study. The consistency of the direction and magnitude of the overall effect and the stability of the results after sensitivity analysis support the study's conclusions.

In conclusion, the results of the present study provide strong evidence that there is no difference in long-term functional outcomes between plate and intramedullary fixation of MSCF. However, the effect of the fixation technique on short-term functional outcomes remains to be clarified. In addition, while the present review indicates that the two fixation techniques may have similar treatment failure rates, the results do not permit any strong assumptions due to the small number of events and wide CI in the present analysis. However, there is evidence that plate fixation is associated with an increased risk of complications not requiring non-routine surgery. Specifically, infections and complications of cosmetic dissatisfaction tend to be higher with plate fixation.

The present study hereby presents the most current level-1 evidence on clinical outcomes following plate vs. intramedullary fixation of MSCF. In line with the conclusions, clinicians may prefer intramedullary fixation for managing MSCF due to its reduced rate of complications. However, individual patient factors and the surgeon's experience shall continue to influence the final choice of fixation for MSCF. Further homogenous high-quality RCTs will further strengthen the evidence on this subject.

\section{Acknowledgements}

Not applicable.

\section{Funding}

No funding was received.

\section{Availability of data and materials}

The datasets used and/or analysed during the current study are available from the corresponding author on reasonable request.

\section{Authors' contributions}

BQ conceived and designed the study. SM and WJ collected the data and performed the literature search. WJ was involved in the writing of the manuscript. All authors have read and approved the final manuscript.

\section{Ethical approval and consent to participate}

Not applicable.

\section{Patient consent for publication}

Not applicable.

\section{Competing interests}

The authors declare that they have no competing interests.

\section{References}

1. Robinson CM: Fractures of the clavicle in the adult.Epidemiology and classification. J Bone Joint Surg Br 80: 476-84, 1998.

2. Nordqvist A and Petersson C: The incidence of fractures of the clavicle. Clin Orthop Relat Res 300: 127-132, 1994.

3. Postacchini F, Gumina S, De Santis P and Albo F: Epidemiology of clavicle fractures. J Shoulder Elb Surg 11: 452-456, 2002.

4. CS NEER II: Nonunion of the clavicle. J Am Med Assoc 172: 1006-1011, 1960.

5. Smekal V, Irenberger A, Struve P, Wambacher M, Krappinger D and Kralinger FS: Elastic stable intramedullary nailing versus nonoperative treatment of displaced midshaft clavicular fractures-a randomized, controlled, clinical trial. J Orthop Trauma 23: 106-112, 2009.

6. Xu B, Lin Y, Wang Z, Cao J, Yang Y, Xia H and Zhang Y: Is intramedullary fixation of displaced midshaft clavicle fracture superior to plate fixation? Evidence from a systematic review of discordant meta-analyses. Int J Surg 43: 155-162, 2017.

7. Wijdicks F-JG, Van der Meijden OAJ, Millett PJ, Verleisdonk EJMM and Houwert RM: Systematic review of the complications of plate fixation of clavicle fractures. Arch Orthop Trauma Surg 132: 617-625, 2012.

8. Wijdicks FJ, Houwert RM, Millett PJ, Verleisdonk EJ and Van der Meijden OA: Systematic review of complications after intramedullary fixation for displaced midshaft clavicle fractures. Can J Surg 56: 58-64, 2013. 
9. Houwert RM, Smeeing DPJ, Ahmed Ali U, Hietbrink F, Kruyt MC and van der Meijden OA: Plate fixation or intramedullary fixation for midshaft clavicle fractures: A systematic review and meta-analysis of randomized controlled trials and observational studies. J Shoulder Elb Surg 25: 1195-1203, 2016.

10. Zhu Y, Tian Y, Dong T, Chen W, Zhang F and Zhang Y: Management of the mid-shaft clavicle fractures using plate fixation versus intramedullary fixation: An updated meta-analysis. Int Orthop 39: 319-328, 2015

11. Gao Y, Chen W, Liu YJ, Li X, Wang HL and Chen ZY: Plating versus intramedullary fixation for mid-shaft clavicle fractures: A systemic review and meta-analysis. PeerJ 4: e1540, 2016.

12. Zhang B, Zhu Y, Zhang F, Chen W, Tian Y and Zhang Y: Meta-analysis of plate fixation versus intramedullary fixation for the treatment of mid-shaft clavicle fractures. Scand J Trauma Resusc Emerg Med 23: 27, 2015.

13. Wang XH, Cheng L, Guo WJ,Li AB, Cheng GJ,Lei T and Zhao YM: Plate versus intramedullary fixation care of displaced midshaft clavicular fractures: A meta-analysis of prospective randomized controlled trials. Medicine (Baltimore) 94: e1792, 2015.

14. Calbiyik M, Ipek D and Taskoparan M: Prospective randomized study comparing results of fixation for clavicular shaft fractures with intramedullary nail or locking compression plate. Int Orthop 41: 173-179, 2017.

15. Fuglesang HFS, Flugsrud GB, Randsborg PH, Oord P, Benth J and Utvåg SE: Plate fixation versus intramedullary nailing of completely displaced midshaft fractures of the clavicle. Bone Joint J 99: 1095-1101, 2017.

16. Constant CR and Murley AH: A clinical method of functional assessment of the shoulder. Clin Orthop Relat Res: 160-164, 1987.

17. Hudak PL, Amadio PC and Bombardier C: Development of an upper extremity outcome measure: The DASH (disabilities of the arm, shoulder and hand) [corrected]. The upper extremity collaborative group (UECG). Am J Ind Med 29: 602-608, 1996.

18. Hussain N, Sermer C, Prusick PJ, Banfield L, Atrey A and Bhandari M: Intramedullary nailing versus plate fixation for the treatment displaced midshaft clavicular fractures: A systematic review and meta-analysis. Sci Rep 6: 34912, 2016.

19. Higgins J, Altman D and Sterne J: Cochrane statistical methods group and the cochrane bias methods group. Chapter 8: Assessing risk of bias in included studies. In: Cochrane handbook for systemic reviews of interventions, version 5. The Cochrane Collaboration, 2011.

20. Lee YS, Lin CC, Huang CR, Chen CN and Liao WY: Operative treatment of midclavicular fractures in 62 elderly patients: Knowles pin versus plate. Orthopedics 30: 959-964, 2007.

21. Tabatabaei S and Shalamzari S: Treatment of displaced midshaft clavicular fractures: A comparison between smooth pin and LCDCP and reconstruction plate fixation. Pakistan J Med Sci 27 1129-1134, 2011.

22. Saha P, Datta P, Ayan S, Garg A, Bandyopadhyay U and Kundu S: Plate versus titanium elastic nail in treatment of displaced midshaft clavicle fractures A comparative study. Indian J Orthop 48: 587-593, 2014

23. Krishnan A, Barot MP, Dave BR, Bang P, Devanand D, Patel D and Jain A: Percutaneous transforaminal endoscopic decompression and cageless percutaneous bone graft transforaminal lumbar interbody fusion: A feasibility study. J Orthop Allied Sci 6: 21-27, 2018

24. Kumar R, Kumar S, Singh D and Goel SC: Role of bone marrow derived autologous mesenchymal stem cells in fracture healing in rabbits. JBJD 32: 7-13, 2017

25. Balachandar S, Mohankumar K and Kathir AS: Outcome of plate and intramedullary fixation of midshaft clavicle fractures: A search for optimal surgical management. Int J Orthop Sci 3: 1050-1061, 2017.

26. Kingsly P, Sathish M and Ismail NDM: Comparative analysis of functional outcome of anatomical precontoured locking plate versus reconstruction plate in the management of displaced midshaft clavicular fractures. J Orthop Surg (Hong Kong) 27 2309499018820351,2019

27. Hulsmans MHJ, van Heijl M, Houwert RM, Hammacher ER, Meylaerts SA, Verhofstad MH, Dijkgraaf MG and Verleisdonk EJ High irritation and removal rates after plate or nail fixation in patients with displaced midshaft clavicle fractures. Clin Orthop Relat Res 475: 532-539, 2017
28. Assobhi JEH: Reconstruction plate versus minimal invasive retrograde titanium elastic nail fixation for displaced midclavicular fractures. J Orthop Traumatol 12: 185-192, 2011.

29. Narsaria N, Singh AK, Arun GR and Seth RRS: Surgical fixation of displaced midshaft clavicle fractures: Elastic intramedullary nailing versus precontoured plating. J Orthop Traumatol 15: 165-171, 2014.

30. Van Der Meijden OA, Marijn Houwert R, Hulsmans M, Wijdicks FJ, Dijkgraaf MG, Meylaerts SA, Hammacher ER, Verhofstad $\mathrm{MH}$ and Verleisdonk EJ: Operative treatment of dislocated midshaft clavicular fractures: Plate or intramedullary nail fixation?: A randomized controlled trial. J Bone Joint Surg Am 97: 613-619, 2015.

31. Zehir S, Zehir R, Şahin E and Çalbıyık M: Comparison of novel intramedullary nailing with mini-invasive plating in surgical fixation of displaced midshaft clavicle fractures. Arch Orthop Trauma Surg 135: 339-344, 2015.

32. Kumar DM, Mishra DA, Kumar DD, Singh DA, Pandey DD and Sinha DAK: A comparative study of displaced midshaft clavicle fracture managed by precontoured locking compression plates and titanium elastic nails. Int J Orthop Sci 4: 116-121, 2018

33. Sahu AK, Lenka BS, Mishra AK, Panda CK and Kar M: A comparative study between plating versus titanium elastic nail system in mid-shaft clavicle fracture management. Int J Res Orthop 4: 741, 2018.

34. Ferran NA, Hodgson P, Vannet N, Williams R and Evans RO: Locked intramedullary fixation vs plating for displaced and shortened mid-shaft clavicle fractures: A randomized clinical trial. J Shoulder Elb Surg 19: 783-789, 2010.

35. Andrade-Silva F, Kojima KD, Joeris A, Silva JS and Rames Mattar Jr: Single, superiorly placed reconstruction plate compared with flexible intramedullary nailing for midshaft clavicular fractures: A prospective, randomized controlled trial. J Bone Joint Surg Am 97: 620-626, 2015.

36. Xiao H, Gao H, Zheng T, Zhao J and Tian Y: Plate fixation versus intramedullary fixation for midshaft clavicle fractures: Meta-analysis of complications and functional outcomes. J Int Med Res 44: 201-215, 2016.

37. Lenza M and Faloppa F: Surgical interventions for treating acute fractures or non-union of the middle third of the clavicle. Cochrane Database Syst Rev 7: CD007428, 2015.

38. Duan X, Zhong G, Cen S, Huang F and Xiang Z: Plating versus intramedullary pin or conservative treatment for midshaft fracture of clavicle: A meta-analysis of randomized controlled trials. J Shoulder Elbow Surg 20: 1008-1015, 2011.

39. Smekal V, Irenberger A, Attal R El, Oberladstaetter J, Krappinger D and Kralinger F: Elastic stable intramedullary nailing is best for mid-shaft clavicular fractures without comminution: Results in 60 patients. Injury 42: 324-329, 2011.

40. Zeng L, Wei H, Liu Y, Zhang W, Pan Y, Zhang W, Zhang C, Zeng B and Chen Y: Titanium elastic nail (TEN) versus reconstruction plate repair of midshaft clavicular fractures: A finite element study. PLoS One 10: e0126131, 2015.

41. Schemitsch LA, Schemitsch EH, Kuzyk P and McKee MD: Prognostic factors for reoperation after plate fixation of the midshaft clavicle. J Orthop Trauma 29: 533-537, 2015.

42. Leroux T, Wasserstein D, Henry P, Khoshbin A, Dwyer T, Ogilvie-Harris D, Mahomed N and Veillette C: Rate of and risk factors for reoperations after open reduction and internal fixation of midshaft clavicle fractures. J Bone Joint Surg Am 96: 1119-1125, 2014.

43. Canadian Orthopaedic Trauma Society: Nonoperative treatment compared with plate fixation of displaced midshaft clavicular fractures. J Bone Joint Surg 89: 1-10, 2007.

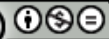

This work is licensed under a Creative Commons Attribution-NonCommercial-NoDerivatives 4.0 International (CC BY-NC-ND 4.0) License. 